Supporting Information

\title{
High-performance supercapacitor device with ultrathick electrodes fabricated from all-cellulose-based carbon aerogel
}

Lei E, Wentao Gan, Jiaming Sun, Zhenwei Wu, Chunhui Ma, Wei Li , and Shouxin

Liu $^{*}$

$\dagger$ Key laboratory of Bio-based Material Science and Technology of Ministry of Education,

Northeast Forestry University, Harbin 150040, China,

*E-mail: liwei19820927@126.com (W. Li.); liushouxin@126.com (S. X. Liu.). 
1. Experimental section

\subsection{Calculation details}

The areal and specific capacitances of the electrodes are all calculated from their GCD profiles by the following equations: $\mathrm{C}_{(\text {areal })}=(\mathrm{I} \times \Delta \mathrm{t}) /(\mathrm{S} \times \Delta \mathrm{V})$; $\mathrm{C}_{(\text {specific })}=(\mathrm{I} \times \Delta \mathrm{t}) /(\mathrm{m} \times \Delta \mathrm{V})$, where $\mathrm{I}$ is the discharge current, $\Delta \mathrm{t}$ is the discharge time, $\mathrm{S}$ is the effective area of the electrode, $\Delta \mathrm{V}$ is the potential window of the discharge process, and $\mathrm{m}$ is the mass of the electrode.

The areal and specific capacitances of the ACDS supercapacitor device are calculated from the GCD profiles according to the following equation: $\mathrm{C}_{(\text {areal })}=(\mathrm{I} \times \Delta \mathrm{t}) /(\mathrm{S} \times \Delta \mathrm{V})$, where $\mathrm{I}$ is the discharge current, $\Delta \mathrm{t}$ is the discharge time, $\mathrm{S}$ is the area of the electrode, $\Delta \mathrm{V}$ is the voltage difference from the beginning to the end of an individual discharge cycle and $\mathrm{m}$ is the total mass of the negative and positive electrode materials.

The capacitance, energy/power densities of the ASCs were calculated based on the total mass of both the anode and cathode materials. Calculation details of the energy (E) and power densities (P): $\mathrm{E}=0.5 \times \mathrm{C} \times \Delta \mathrm{V}^{2} ; \mathrm{P}=\mathrm{E} / \Delta \mathrm{t}$, where $\mathrm{C}$ is the areal or specific capacitance of the ACDS supercapacitor device, $\Delta \mathrm{t}$ and $\Delta \mathrm{V}$ are the discharge time and potential difference of an individual discharge cycle.

\subsection{Electrochemical measurements of CA-T-t.}

To test the effects of $\mathrm{CO}_{2}$ activation conditions on the electrochemical performance, electrochemical techniques (CV, GCD and EIS) were performed using an electrochemical analyzer (Solartron 1400 UK). A platinum gauze and 
$\mathrm{Hg} / \mathrm{HgO}$ electrode were used as counter and the reference electrode in threeelectrode system (6 M KOH), respectively. 

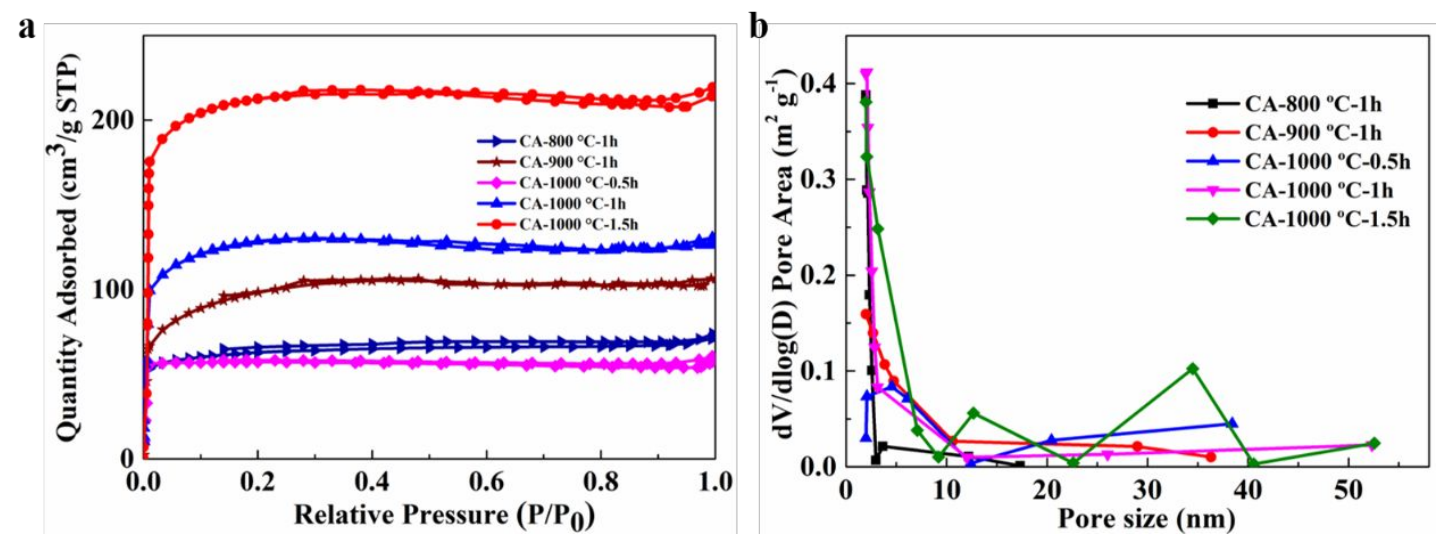

Figure S1. (a) $\mathrm{N}_{2}$ adsorption/desorption isotherms and (b) pore size distributions curve of CA-T-t. 

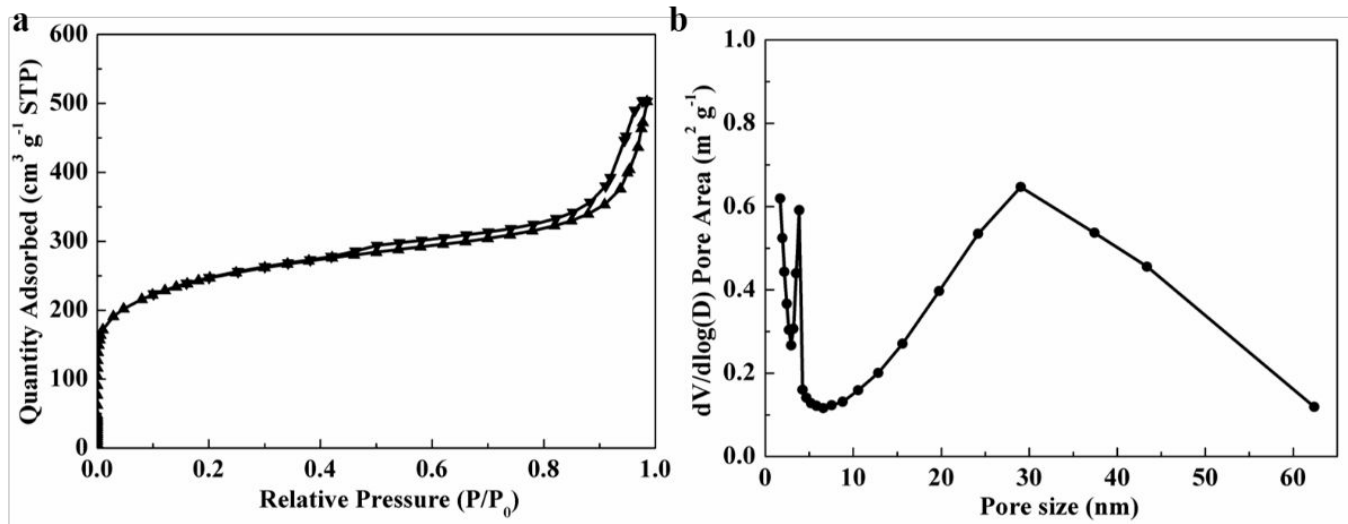

Figure S2. (a) $\mathrm{N}_{2}$ adsorption-desorption isotherms and (b) pore size distributions of CA-R. 

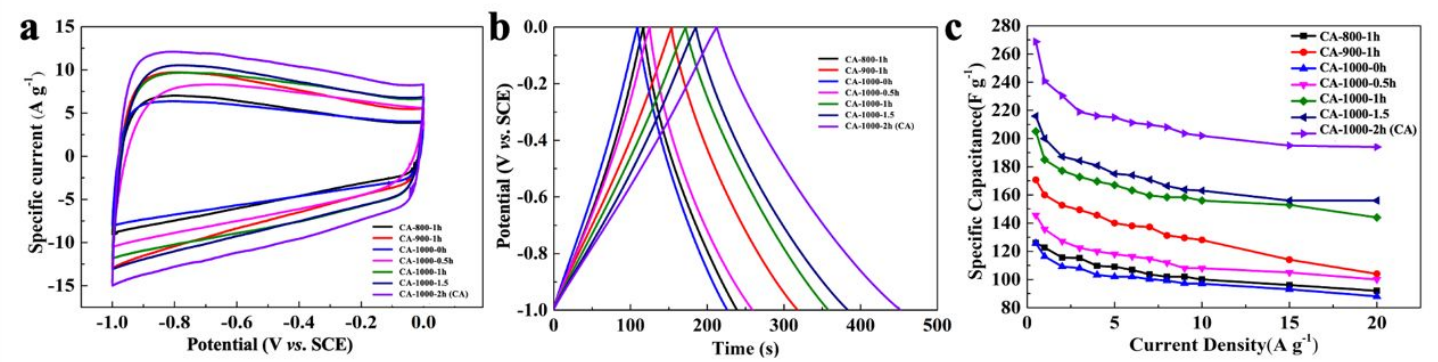

Figure S3. Electrochemical capacitive behaviors of CA-T-t. (a) CV curves at a scan rate of $50 \mathrm{mV} \mathrm{s}^{-1}$, (b) GCD curves at $1 \mathrm{~A} \mathrm{~g}^{-1}$, and (c) the specific capacitances of carbon aerogels calculated from GCD curves. 


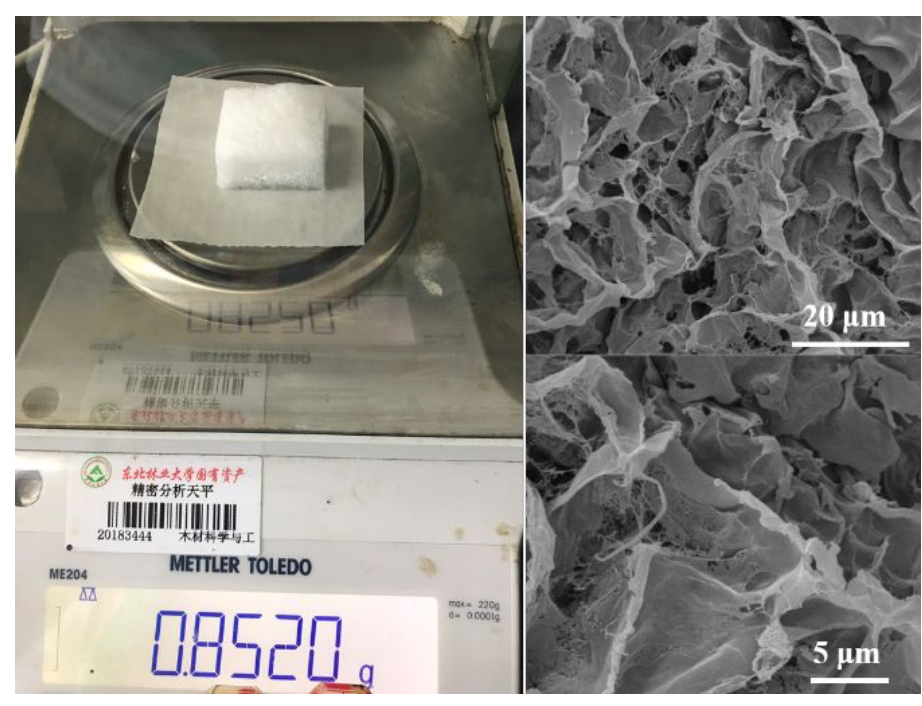

Figure S4. (a) Photograph of a piece of cellulose aerogel on the balance (without adding acetylene black). (b-c) SEM images of cellulose aerogel. 


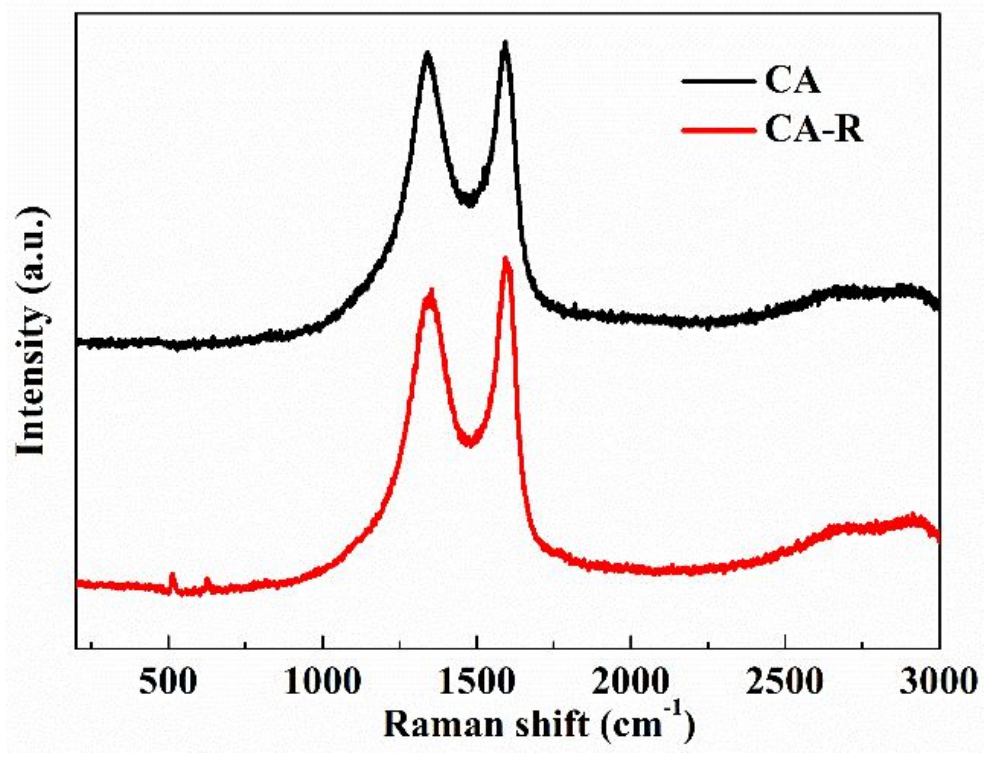

Figure S5. Raman spectra of CA and CA-R 


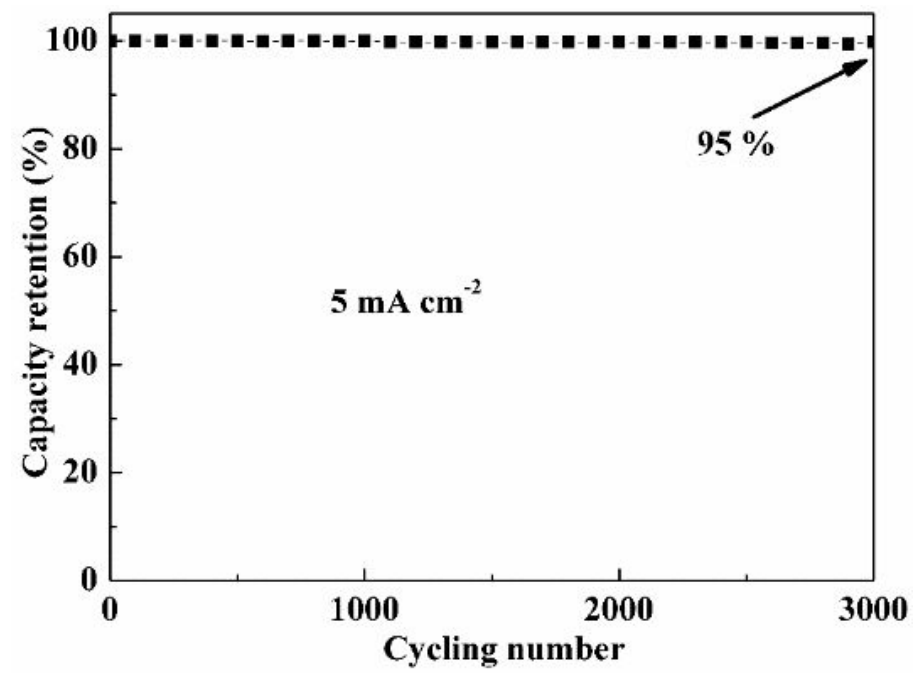

Figure S6. Cycling stability test over 3000 cycles at a current density of $5 \mathrm{~mA} \mathrm{~cm}^{-2}$ of CA. 


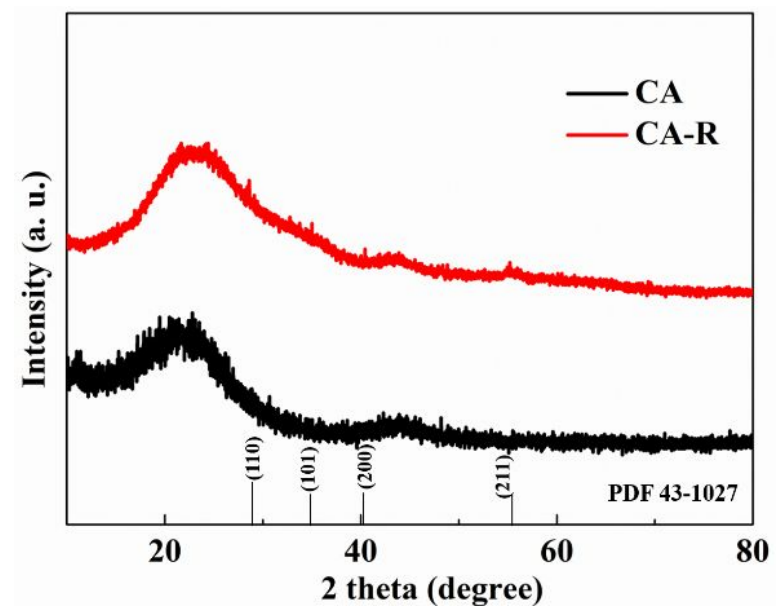

Figure S7. XRD patterns of the CA and CA-R the standard JCPDS file. 

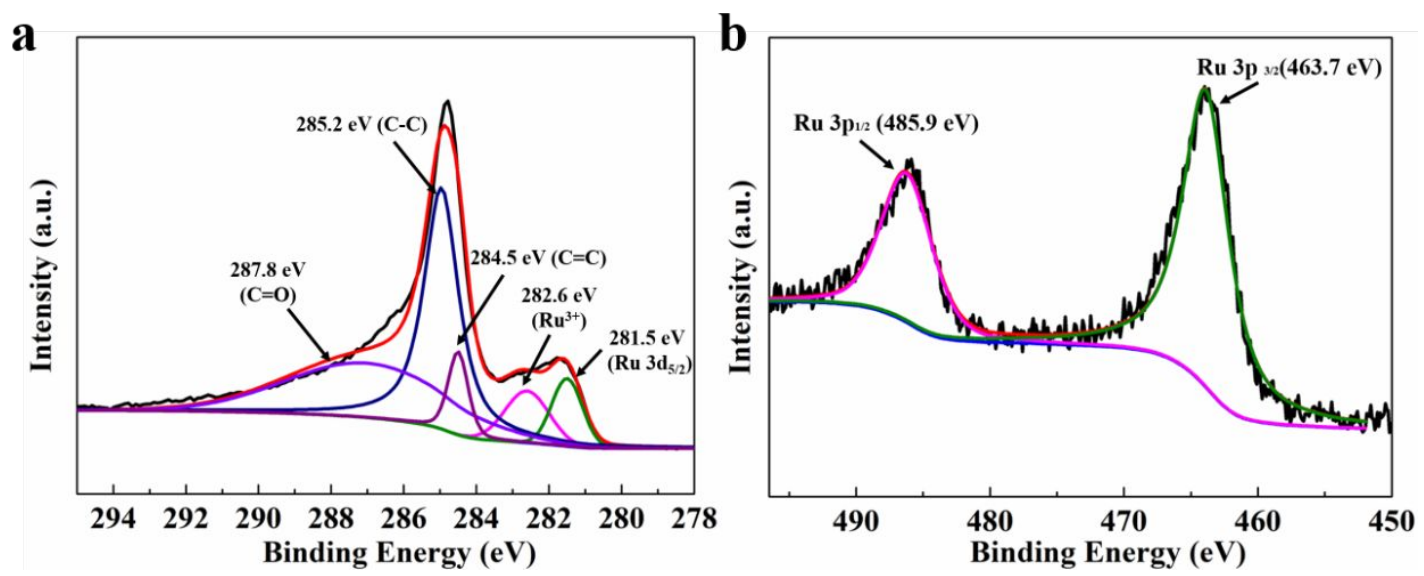

Figure S8. (a) peak fitted high-resolution of C1s region and (b) high-resolution

$\mathrm{Ru} 3 \mathrm{p}$ spectrum of CA-R. 


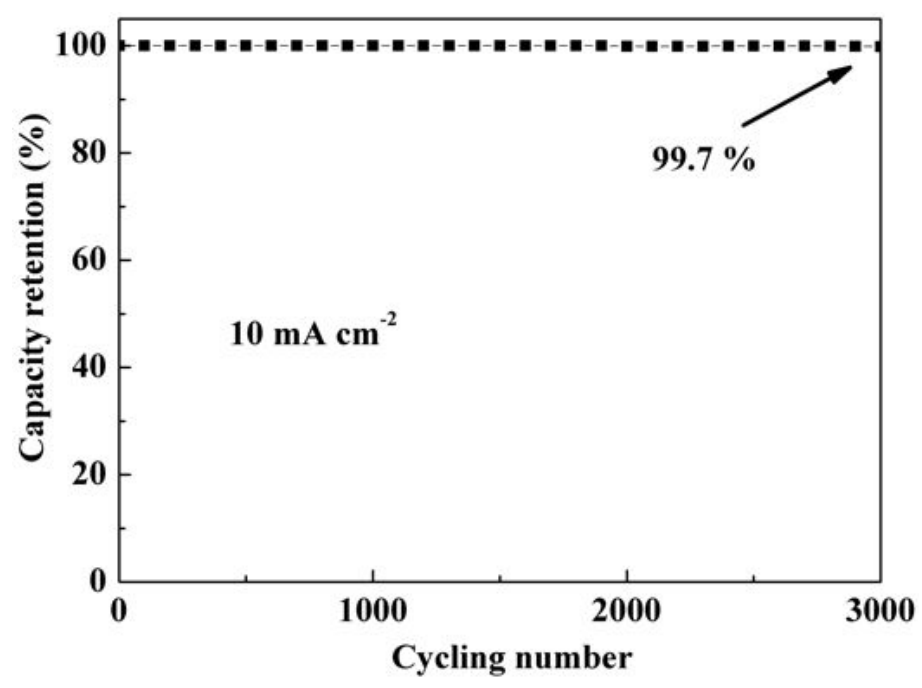

Figure S9. Cycling stability test of CA-R over 3000 cycles at a current density of 5 $\mathrm{mA} \mathrm{cm}{ }^{-2}$. 


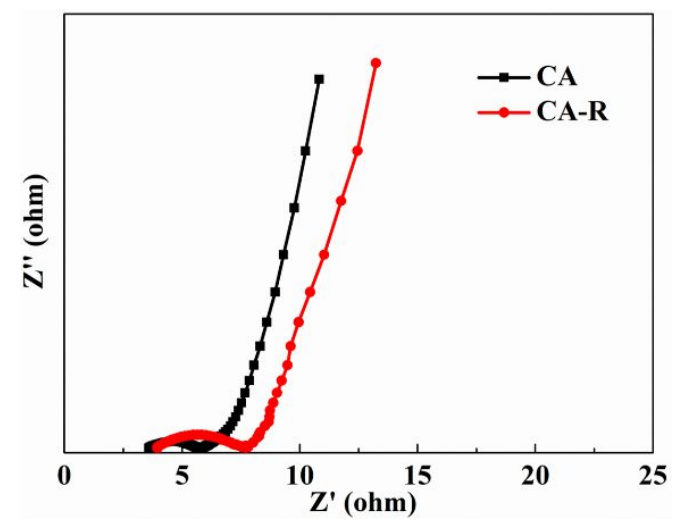

Figure S10. The impedance spectra of CA and CA-R. 


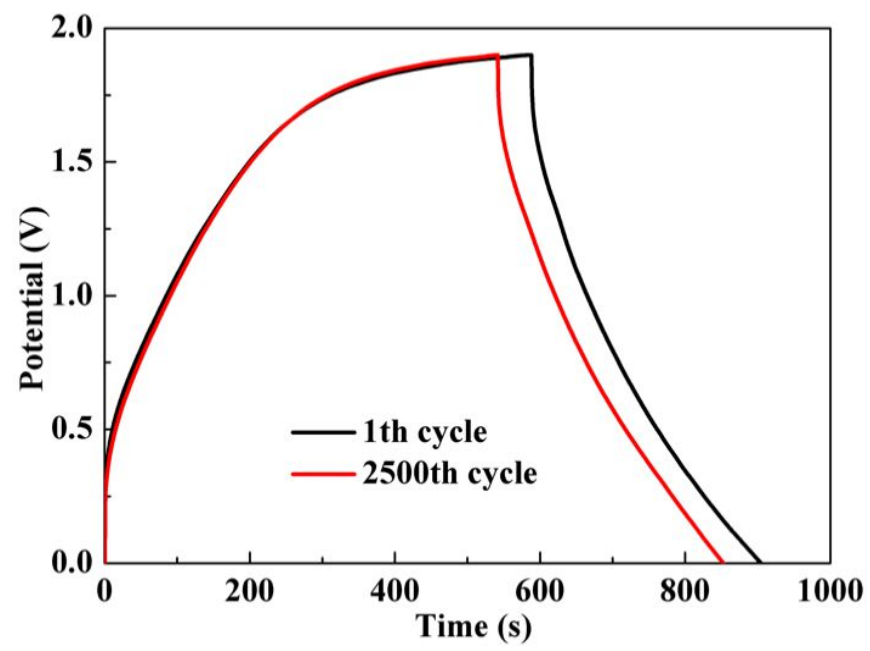

Figure S11. GCD curves of ACAS at the 1th and 2500th. 
Table S1. Pore structure parameters of carbon aerogels.

\begin{tabular}{cccc}
\hline Sample & $\begin{array}{c}\mathbf{S}_{B E T} \\
\left(\mathrm{~m}^{2} \mathbf{g}^{-1}\right)\end{array}$ & $\begin{array}{c}\text { Total pore volume } \\
\left(\mathrm{cm}^{3} \mathbf{g}^{-1}\right)\end{array}$ & $\begin{array}{c}\text { Micropore Volume } \\
\left(\mathrm{cm}^{3} \mathbf{g}^{-1}\right)\end{array}$ \\
\hline CA-800-1 & 195.32 & 0.11 & 0.06 \\
CA-900-1 & 332.08 & 0.15 & 0.07 \\
CA-1000-0 & 9.11 & 0.003 & 0.002 \\
CA-1000-0.5 & 224.97 & 0.08 & 0.07 \\
CA-1000-1 & 337.27 & 0.16 & 0.09 \\
CA-1000-1.5 & 655.15 & 0.33 & 0.20 \\
CA (CA-1000-2) & 1030.66 & 0.83 & 0.31 \\
CA-R & 829.01 & 0.77 & 0.24 \\
\hline
\end{tabular}

